\title{
Effect of Twisted-Tape Turbulators and Nanofluid on Heat Transfer in a Double Pipe Heat Exchanger
}

\author{
Heydar Maddah, ${ }^{1}$ Reza Aghayari, ${ }^{1}$ Morshed Farokhi, ${ }^{2}$ \\ Shabnam Jahanizadeh, ${ }^{1}$ and Khatere Ashtary ${ }^{3}$ \\ ${ }^{1}$ Department of Chemistry, Sciences Faculty, Islamic Azad University, Arak Branch, Arak, Iran \\ ${ }^{2}$ Department of Chemical Engineering, Islamic Azad University, Mahshahr Branch, Mahshahr, Iran \\ ${ }^{3}$ Department of Chemistry, Islamic Azad University, Saveh Branch, Saveh 39197-15179, Iran \\ Correspondence should be addressed to Reza Aghayari; reza.aghayari63@yahoo.com
}

Received 18 August 2014; Revised 30 October 2014; Accepted 30 October 2014; Published 19 November 2014

Academic Editor: Michael Fairweather

Copyright (C) 2014 Heydar Maddah et al. This is an open access article distributed under the Creative Commons Attribution License, which permits unrestricted use, distribution, and reproduction in any medium, provided the original work is properly cited.

\begin{abstract}
Heat transfer and overall heat transfer in a double pipe heat exchanger fitted with twisted-tape elements and titanium dioxide nanofluid were studied experimentally. The inner and outer diameters of the inner tube were 8 and $16 \mathrm{~mm}$, respectively, and cold and hot water were used as working fluids in shell side and tube side. The twisted tapes were made from aluminum sheet with tape thickness $(d)$ of $1 \mathrm{~mm}$, width $(W)$ of $5 \mathrm{~mm}$, and length of $120 \mathrm{~cm}$. Titanium dioxide nanoparticles with a diameter of $30 \mathrm{~nm}$ and a volume concentration of $0.01 \%(\mathrm{v} / \mathrm{v})$ were prepared. The effects of temperature, mass flow rate, and concentration of nanoparticles on the overall heat transfer coefficient, heat transfer changes in the turbulent flow regime $(\operatorname{Re} \geq 2300)$, and counter current flow were investigated. When using twisted tape and nanofluid, heat transfer coefficient was about 10 to 25 percent higher than when they were not used. It was also observed that the heat transfer coefficient increases with operating temperature and mass flow rate. The experimental results also showed that $0.01 \% \mathrm{TiO}_{2}$ / water nanofluid with twisted tape has slightly higher friction factor and pressure drop when compared to $0.01 \% \mathrm{TiO}_{2}$ / water nanofluid without twisted tape. The empirical correlations proposed for friction factor are in good agreement with the experimental data.
\end{abstract}

\section{Introduction}

Lehigh heat exchange devices are used in industry for heat transfer between two fluids. Heat transfer is a mechanism for movement. Viscous fluids such as water are used in the twintube exchangers. The tube exchangers are widely used for the following reasons: creation of a large surface for heat transfer, reduction in size, good mechanical design, well-established technique, and usability for a wide range of substances. The major disadvantage of these converters can be explained as follows: for large thermal load, two-way exchange of large volumes occupies. The unit price of heat transfer area is relatively high. Application of nanotechnology in classical thermal designs leads to the production of a new class of heat transfer fluids, that is, nanofluids (Choi [1]). Since conventional heat transfer (HT) fluids including water, oil, and ethylene glycol (EG) show relatively poor HT characteristics, NF has been introduced. NFs are formed by dispersing solid particles, fibers, or tubes of 1 to $50 \mathrm{~nm}$ length in conventional HT fluids. There are significant characteristics associated with NFs such as high HT rate, low fluctuation ability through passages, and thermal homogeneity. The advances in nanotechnology have resulted in the development of a category of fluids termed nanofluids, first used by a group at the Argonne National Laboratory in America in 1995. Aghayari et al. [2] reported experimental results which illustrated the dispersion of the heat transfer and overall heat transfer coefficient of $\mathrm{AL}_{2} \mathrm{O}_{3}$ nanoparticles in liquid for turbulent flow in a double pipe heat exchanger. Impacts of the Reynolds number, volume fraction, temperature, and nanoparticle source on the overall heat transfer coefficient have been investigated. The experimental results showed that the heat transfer coefficient increases with the Reynolds number and the particle concentration. Aluminum oxide nanofluid with concentrations of 0.2 and 0.3 


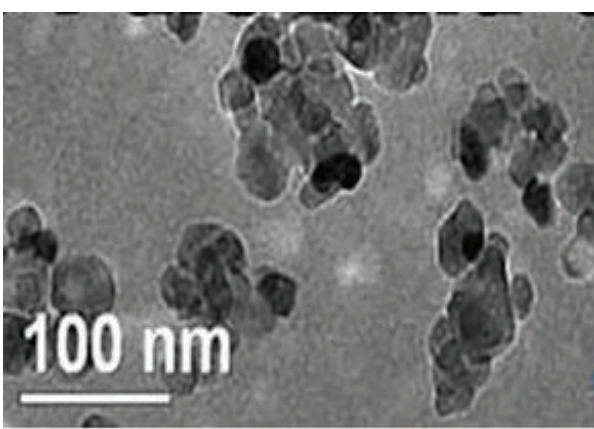

(a)

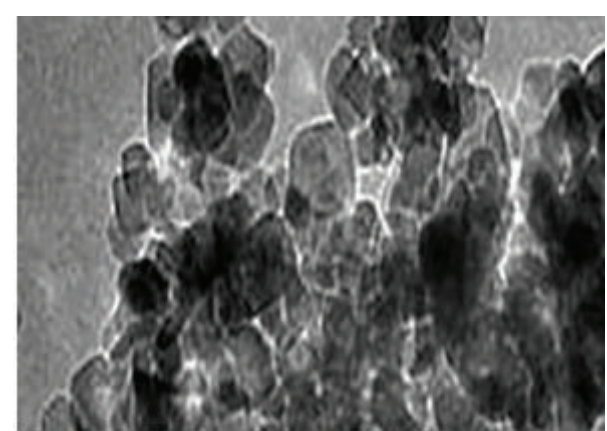

(b)

FIGURE 1: TEM photographs of $\mathrm{TiO}_{2}$ particles.

had high thermal efficiency compared to the base fluid. For example, this amount is 1450000 for water at a constant mass flow rate and a temperature of $50^{\circ} \mathrm{C}$. This amount is 1565000 and 1580000 for the nanofluid at the concentrations of 0.2 and 0.3 , respectively. Thermal efficiency of water and nanofluid with the concentration of 0.1 is 1103842 and 1123123 , respectively (in Reynolds of 23000), which is approximately $1.71 \%$ higher than the heat transfer of the base fluid. This increase can be attributed to the immigration of the particles, nonuniform distribution of the thermal conductivity, and viscosity of the fluid which decreases the boundary layer thickness, resulting in the delay in the development of the thermal boundary layer. Probably, Duangthongsuk and Wongwises [3] were the first who suggested the addition of solid particles in nanometric size into a base fluid and reported enhancement of thermal conductivity compared to base fluid. Many studies have been done in order to evaluate the heat transfer performance and flow characteristics of various nanofluids in both the laminar and the turbulent flow regimes [4-14]. Results of these studies proved that the inclusion of nanoparticles improves the thermal conductivity compared to the conventional fluid and increases heat transfer rate with the nanoparticle concentration. Naphon and Suchana [15] studied experimentally the effect of twisted wire brush inserts of water turbulent flow on the heat transfer enhancement in a horizontal concentric tube. It was observed that the heat transfer rate and the friction factor of the plain tube with 300-twisted-wire brush insert were higher than those of the plain tube with 200- and 100-twistedwire brush insert and subsequently higher than those of the plain tube without twisted wire brush insert. Wongcharee and Eiamsa-Ard [16] investigated experimentally the influence of $\mathrm{CuO}$ /water nanofluid and corrugated tube equipped with twisted tape on the thermal performance. The maximum thermal performance factor of 1.57 was found in counter arrangements at twist ratio of 2.7 and Reynolds number of 6200 .

\section{Nanofluid Preparation}

The nanofluid used in the experiment was $99.9 \%$ pure $\mathrm{TiO}_{2}$ predispersed in water. In the present study, $\mathrm{TiO}_{2}$ nanoparticles of size $30 \mathrm{~nm}$ were mixed with distilled water and stabilizers and then sonicated continuously by ultrasonic vibrator (Toshiba, India) generating ultrasonic pulses of $100 \mathrm{~W}$ at $36 \pm 3 \mathrm{kHz}$ for $5 \mathrm{~h}$ to break down agglomeration of the nanoparticles, prior to being used as the working fluid. The desired volume concentration used in this study was $0.01 \%$. The nanofluid was mixed with deionized water to prepare experimental nanofluids with concentrations less than $4 \%$. Nanoparticles were found to be stable and the stability lasted over a week; no intermediate mixing was considered necessary. No significant difference in measured density was observed. The distribution of the primary $\mathrm{TiO}_{2}$ nanoparticles can be observed under a transmission electron microscope (TEM). As shown in Figure 1, nanoparticles are in approximately spherical shape with an average diameter of $30 \mathrm{~nm}$ (Table 1).

\section{Apparatus}

The experimental investigation of heat transfer characteristic of nanofluid was carried out using the experimental apparatus as shown in Figures 2 and 3. It mainly consists of a test section, receiving tanks in which working fluids are stored, heating and cooling system, thermometer, flow meter, rotameter, pressure measurement system, and data acquisition system. The working fluids were circulated through the loop by using variable speed pumps of suitable capacity. The test section is of $1.2 \mathrm{~m}$ length with counter flow path within horizontal double pipe heat exchanger in which hot nanofluid was applied inside the tube while cooling water was directed through the annulus. The inside pipe is made of a soft steel tube with the inner diameter of $6 \mathrm{~mm}$, outer diameter of $8 \mathrm{~mm}$, and thickness of $2 \mathrm{~mm}$ while the outside pipe is of steel tube with the inner diameter of $14 \mathrm{~mm}$, outer diameter of $16 \mathrm{~mm}$, and thickness of $2 \mathrm{~mm}$. The twisted tapes were made from aluminum sheet with tape thickness $(d)$ of $1 \mathrm{~mm}$, width $(W)$ of $5 \mathrm{~mm}$, and length of $120 \mathrm{~cm}$. The tape thickness of $1 \mathrm{~mm}$ was chosen to avoid an additional friction in the system that might occur by the thicker tape. To produce the modified twisted tape, the typical twists changed by changing twist ratio and geometrical progression ratio along the twist (Figure 4).

To measure the inlet and outlet temperature of the nanofluid and cold water at the inlet and outlet of the test 
TABLE 1: Physical properties of the nanoparticles.

\begin{tabular}{lcccccc}
\hline Types of nanoparticles & Nanosized particles & Special surface & Purity percent & Appearance & The apparent density \\
\hline $\mathrm{TiO}_{2}$ & $30 \mathrm{~nm}$ & $>60 \mathrm{~m}^{2} / \mathrm{g}$ & +99.9 & White powder & & $0.7 \mathrm{~g} / \mathrm{m}^{3}$ \\
\hline & & Certificate of analysis (content of elements) & & & \\
$\mathrm{TiO}_{2}$ & $\mathrm{Fe}$ & $\mathrm{Cr}$ & $\mathrm{Co}$ & $\mathrm{pb}$ & $\mathrm{As}$ & $\mathrm{Hg}$ \\
\hline$\geq 99.9 \%$ & $\leq 0.005 \%$ & $\leq 0.005 \%$ & $\leq 0.01 \%$ & $\leq 66 \mathrm{ppm}$ & $\leq 120 \mathrm{ppm}$ & $\leq 78 \mathrm{ppm}$ \\
\hline
\end{tabular}

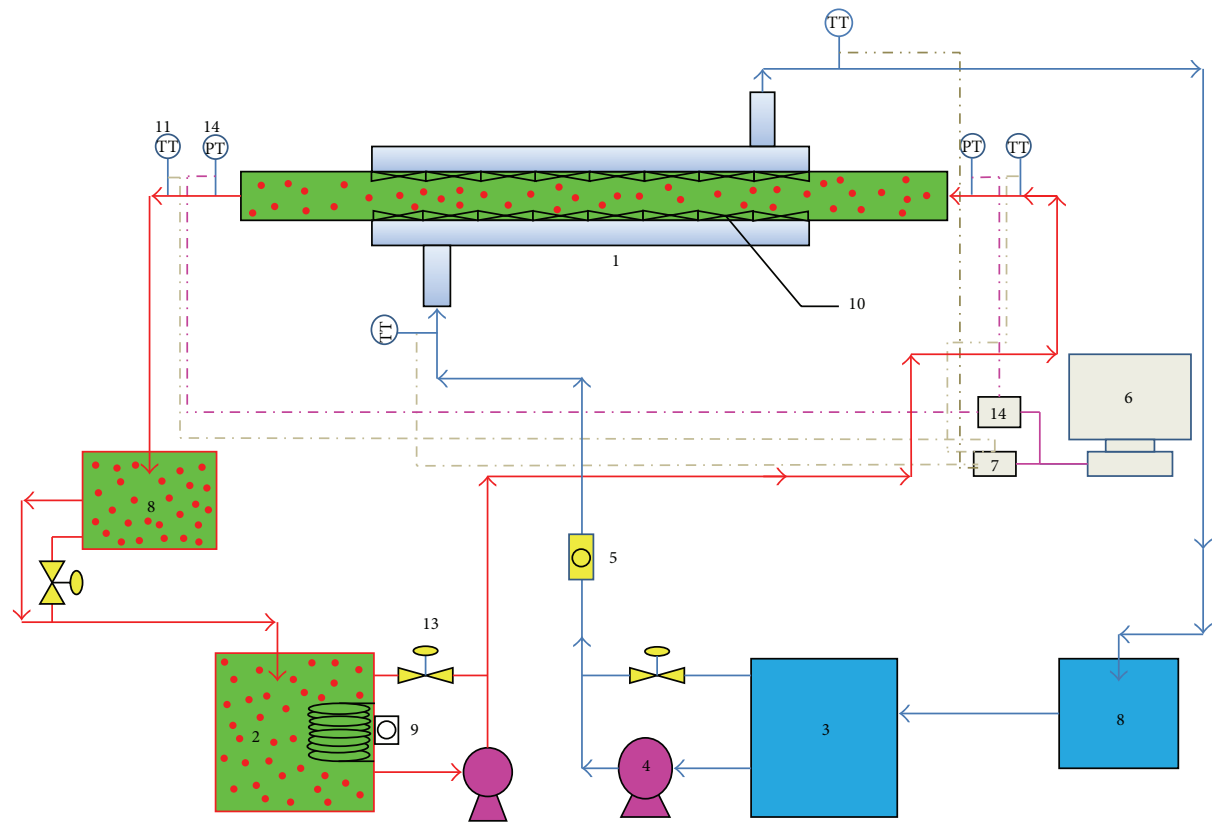

(1) Double pipe heat exchanger

(8) Receiving tank

(2) Nanofluid tank

(9) Thermostat

(3) Water tank

(10) Twisted tapes

(4) Pump

(11) Calibrated RTD

(5) Rotameter

(12) Rotameter

(6) Computer

(13) Control valve

(7) Data logger

(14) Pressure scanner

FIGURE 2: Schematic diagram of the experimental setup.

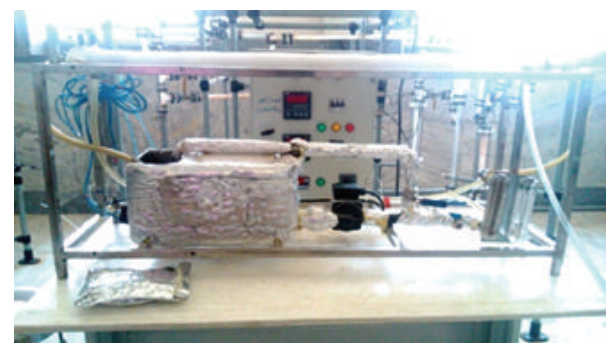

Figure 3: Experimental setup.

section, 4 thermocouples of type J were used. All of the thermocouples were calibrated before fixing them. All four evaluated temperature probes were connected to the data logger sets. An electric heater and a thermostat installed on

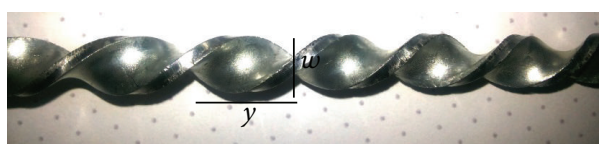

FIGURE 4: Geometries of typical twisted tape.

it were used to maintain the temperature of the nanofluid. During the test, the mass flow rate and the inlet and outlet temperatures of the nanofluid and cold water were measured. To measure the pressure drop across the test section, differential pressure transmitter was mounted at the pressure tab located at the inlet and outlet of the section. The nanofluid flow rate was measured by a magnetic flow meter which was placed at the entrance of the test section. For each test run, it was essential to record the data of the temperature, 
volumetric flow rates, and pressure drop across the section at steady state conditions. Two storage tanks made of stainless steel at capacity of 15 lit were used to collect the fluids leaving the test section. Hot nanofluid was pumped from the fluid tank through the inner tube included twisted tapes at different Reynolds number between 10000 and 27500. To ensure the steady state condition for each run, the period of around 15-20 minutes depending on Reynolds number and twisted tapes was taken prior to the data record.

\section{Data Reduction}

In the present study, the $\mathrm{TiO}_{2}$ nanoparticles dispersed in water with volume concentration of $0.01 \%(\mathrm{v} / \mathrm{v})$. During the test, cold water absorbed heat from hot nanofluid. The heat transfer rate from the heating fluid was calculated from the following equation:

$$
\mathrm{Q}_{\mathrm{nf}}=\dot{m}_{\mathrm{nf}} C p_{\mathrm{nf}}\left(T_{\mathrm{out}}-T_{\mathrm{in}}\right)_{\mathrm{nf}},
$$

where $Q_{\mathrm{nf}}$ is the heat transfer rate of the nanofluid and $\dot{m}_{\mathrm{nf}}$ is the mass flow rate of the nanofluid. The heat transfer rate in the cooling water was calculated from the following equation:

$$
Q_{w}=\dot{m}_{w} C p_{w}\left(T_{\text {out }}-T_{\text {in }}\right)_{w} .
$$

In this study, the supplied heat by the hot nanofluid was found to be $3 \%$ higher than the received heat. This deviation can be interpreted by convection and radiation heat loss along the test section. The average heat transfer rate is

$$
Q_{\text {ave }}=\frac{Q_{w}+Q_{\mathrm{nf}}}{2} \text {. }
$$

The flow regime can be defined from Reynolds number based on the flow rate at the inlet of the test tube. For purely viscous non-Newtonian fluid, the Reynolds number is defined as follows:

$$
\mathrm{Re}=\frac{\rho_{\mathrm{nf}} v_{\mathrm{nf}}^{2-n} d_{i}^{n}}{m \gamma^{n-1}}
$$

where $v_{\mathrm{nf}}$ is the mean velocity of the nanofluid and $d_{i}$ is the diameter of the tube.

Friction factor can be calculated from the following equation:

$$
f_{\mathrm{nf}}=\frac{\Delta P_{\mathrm{nf}}}{\left(L / d_{i}\right) \rho_{\mathrm{nf}}\left(v_{\mathrm{nf}}^{2} / 2\right)},
$$

where $f_{\mathrm{nf}}$ is the friction factor of the nanofluid, $\Delta P_{\mathrm{nf}}$ is the measured pressure drop of the nanofluid, and $L$ is the length of the tube.

To compare friction factor, Blasius correlation [17] for water and Duangthongsuk and Wongwises correlation [9] for nanofluid were employed:

Blasius correlation:

$$
f=0.316 \mathrm{Re}^{-0.25}
$$

and Duangthongsuk and Wongwises correlation:

$$
f_{\mathrm{nf}}=0.961 \varphi^{0.052} \operatorname{Re}_{\mathrm{nf}}^{-0.375} .
$$

The Prandtl number and Peclet number of the nanofluid can be evaluated from the following equations:

$$
\begin{aligned}
\operatorname{Pr}_{\mathrm{nf}} & =\frac{m \gamma^{n-1} C p_{\mathrm{nf}}}{K_{\mathrm{nf}}}, \\
\mathrm{Pe}_{\mathrm{nf}} & =\frac{v_{\mathrm{nf}} d_{p}}{\alpha_{\mathrm{nf}}}
\end{aligned}
$$

where $d_{p}$ is the diameter of the nanoparticles and $\alpha_{\mathrm{nf}}$ is the thermal diffusivity of the nanofluid. Consider

$$
\begin{aligned}
T_{(\text {hot }) \text { average }} & =\frac{T_{(\text {hot }(\text { out }))}+T_{(\text {hot(in)) }}}{2}, \\
T_{(\text {cold)average }} & =\frac{T_{(\text {cold(in) })}+T_{(\text {cold }(\text { out }))}}{2} .
\end{aligned}
$$

To calculate heat capacity of nanofluid, a famous relationship can be used:

$$
\left(C_{p}\right)_{\mathrm{nf}}=\left(1-\varphi_{v}\right)\left(C_{p}\right)_{\text {basis flow }}+\varphi_{v}(\rho C)_{\text {particle }} .
$$

The appropriate correlations to evaluate density of nanofluids were presented by Pak and Cho [18] which were defined as follows:

$$
\begin{gathered}
\rho_{\mathrm{nf}}=\varphi \rho_{\mathrm{np}}+(1-\varphi) \rho_{\mathrm{bf}}, \\
Q_{(\text {average })}=U A \Delta T_{(\text {log main temperature difference) }}, \\
U=\frac{Q_{(\text {average })}}{A_{\text {(average) }} \Delta T_{(\log \text { main temperature difference })}},
\end{gathered}
$$

$$
\begin{aligned}
& \Delta T_{\text {(log main temperature difference) }} \\
& \quad=\frac{\left(T_{\text {hot (out) }}-T_{\text {cold(in) }}\right)-\left(T_{\text {hot(in) }}-T_{\text {cold(out) }}\right)}{\ln \left[\left(T_{\text {hot(out) }}-T_{\text {cold(in) }}\right) /\left(T_{\text {hot(in) }}-T_{\text {cold(out })}\right)\right]},
\end{aligned}
$$

where the effective thermal conductivity $\left(K_{\mathrm{nf}}\right)$ of the nanofluids can be evaluated by Timofeeva correlations model that is given as follows [19]:

$$
K_{\mathrm{nf}}=[1+3 \varphi] K_{\mathrm{bf}}
$$

Viscosity of the nanofluid is calculated using Einstein [20] correlations as below:

$$
\mu_{\mathrm{nf}}=(1+2.5 \varphi) \mu_{\mathrm{bf}}
$$

Batchelor [21] introduced a correlation for calculating the viscosity of nanofluids with spherical shape nanoparticles, which is defined as

$$
\mu_{\mathrm{nf}}=\left(1+2.5 \varphi+6.2 \varphi^{2}\right) \mu_{\mathrm{bf}}
$$

\section{Discussion and Results}

When using titanium dioxide NF (nanofluid) as hot fluid, the heat transfer rate increases as opposed to that of water, that is, base fluid. This finding is depicted in Figures 5 and 6 


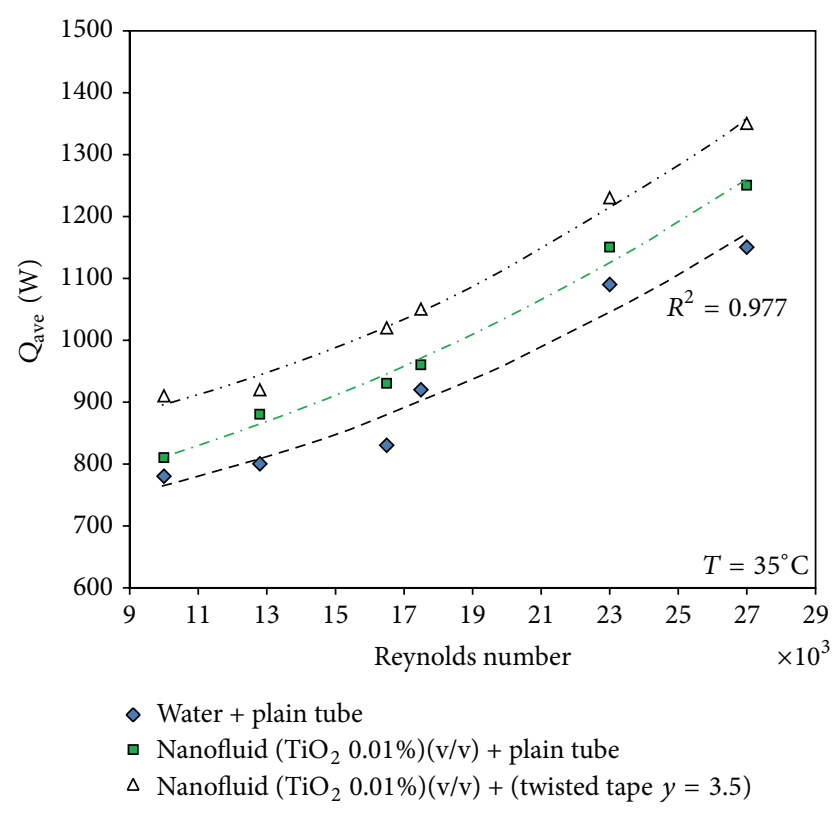

Figure 5: Variation of mean heat flow rate with Reynolds number.

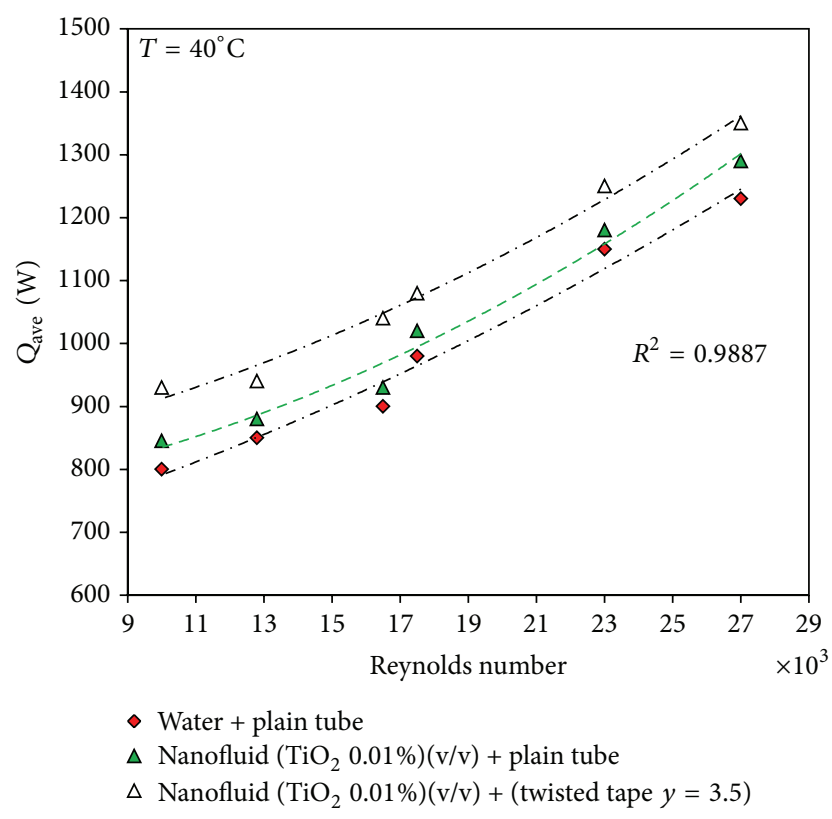

FIGURE 6: Variation of mean heat flow rate with Reynolds number.

where, at Reynolds number equal to 23000 , the mean $\mathrm{HT}$ (heat transfer) rate values for water at $35^{\circ} \mathrm{C}$ and $40^{\circ} \mathrm{C}$ are approximated to 1100 and 1180 Watts, respectively. As for NF $0.01 \%(v / v)$ at identical Reynolds number the mean HT rate values at the above noted temperatures are 1180 and 1240 Watts, respectively. For example, in Figures 5, 6, 7, and 8 , at Reynolds number equal to 23000 , the mean $\mathrm{HT}$ (heat transfer) rate values for water at $35^{\circ} \mathrm{C}$ and $40^{\circ} \mathrm{C}$ are approximated to $1230,1300,2700$, and 2900 , respectively. One of the reasons for this increase can be attributed to the turbulence. The heat transfer rate is higher for the twist

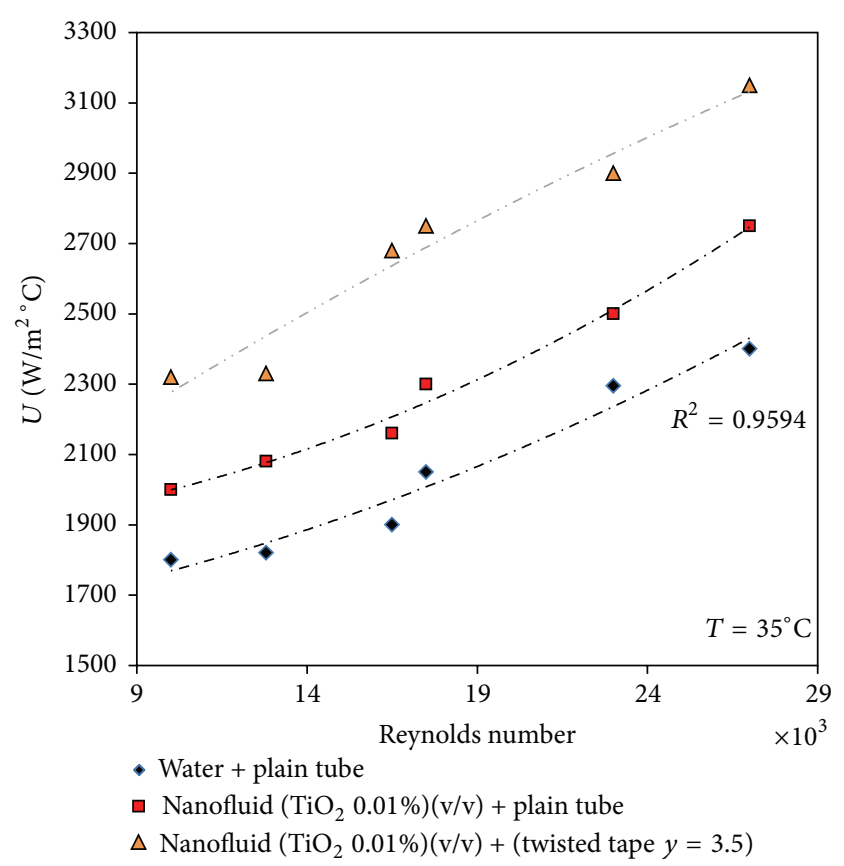

FIGURE 7: Variation of overall heat transfer coefficient with Reynolds number.

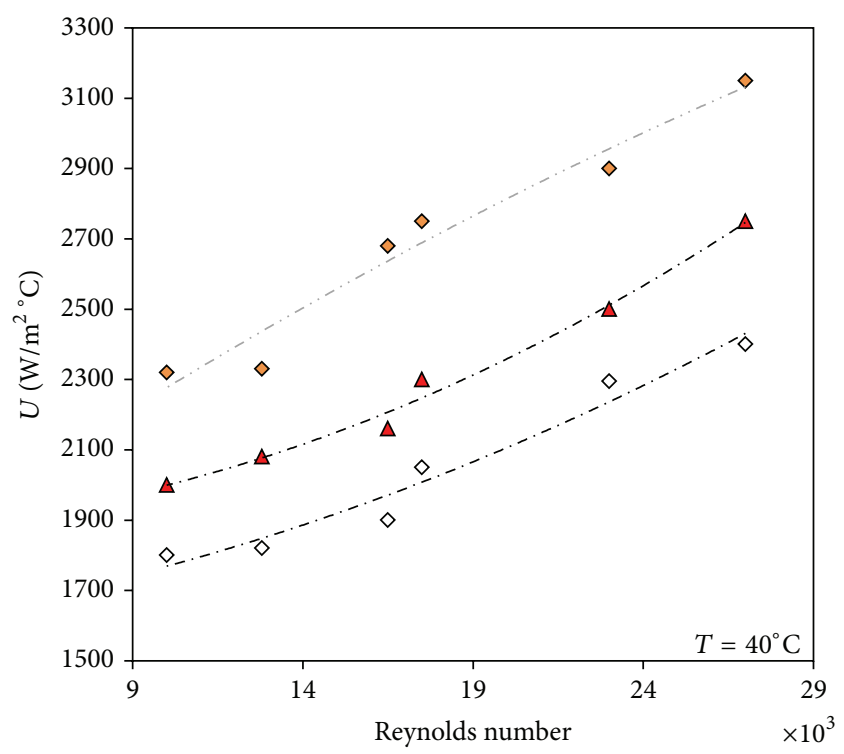

$\diamond$ Water + plain tube

$\Delta$ Nanofluid $\left(\mathrm{TiO}_{2} 0.01 \%\right)(\mathrm{v} / \mathrm{v})+$ plain tube

$\diamond$ Nanofluid $\left(\mathrm{TiO}_{2} 0.01 \%\right)(\mathrm{v} / \mathrm{v})+($ twisted tape $y=3.5)$

FIGURE 8: Variation of overall heat transfer coefficient with Reynolds number.

tape set than the plain tube, because of strong swirl flow in the twist tape. Due to the tangential velocity component and smaller flow cross-sectional area, the mixing of fluid between fluid at the wall region and fluid at the core region, induced by the generated centrifugal force, has significant ability to enhance heat transfer rate. The values of overall 
heat transfer coefficient of the nanofluid as compared to those of the base fluid in both laminar and turbulent regimes are higher. One explanation can be the affecting parameters including Reynolds numbers for the hot and cold fluid, the size of nanoparticles, the type of heat exchanger, and NF temperature. It is evident that the friction factor continues to decrease with Reynolds number. As expected, the friction factor obtained from the tube with twisted-tape insert is significantly higher than that without twisted-tape insert.

Figures 7 and 8 represent the dependency of OHTCNF (overall heat transfer coefficient of nanofluid) on Reynolds number. According to these figures, as Reynolds number and temperature increase in NF containing titanium dioxide $0.01 \%(\mathrm{v} / \mathrm{v})$ in water as base fluid, the OHTCNF increases. For the sake of argument, at Reynolds number equal to 23000 for water at $35^{\circ} \mathrm{C}$ and $40^{\circ} \mathrm{C}$ the OHTCNF values are 2200 and 2300 , respectively. As for NF $0.01 \%$ (v/v) at identical Reynolds number, the overall heat transfer coefficient values at the above noted temperatures are 2480 and 2590 , respectively. The experimental results show that titanium dioxide NF has higher overall heat transfer efficiency in comparison with water as base fluid. If mass flow rate increases, then rise in temperature has severe effect on the overall heat transfer coefficient. Therefore, not only nanoparticle concentration but also the NF operating temperature and the corresponding effects on dispersion would all affect the heat transfer of NF. It is worth noting that particle surface properties and heat exchanger design are important and must be taken into consideration.

One reason for this difference in heat transfer at high Reynolds numbers is the high viscosity of nanofluid. In general, the fluid containing rod-shaped particles, due to severe reactions, has high viscosity and high density in shear flow. Particle concentration and movement of particles in the flow are other factors that affect the heat transfer.

The transitional move is assumed the main mechanism for increasing the thermal conductivity of nanoparticles. The mobility of finer particles increases the coefficient of thermal conductivity of nanofluids more than the coarse particles. Twisted-tape inserts increase the heat transfer coefficients with relatively small increase in the pressure drop. They are known to be one of the earliest swirl flow devices employed in the single phase heat transfer processes. Because of the design and application convenience they have been widely used over decades to generate the swirl flow in the fluid. Size of the new heat exchanger can be reduced significantly by using twisted tapes in the new heat exchanger for a specified heat load. Thus, it provides an economic advantage over the fixed cost of the equipment. Twisted tapes can be also used for retrofitting purpose. They can increase the heat duties of the existing double tube heat exchangers. Twisted tapes with multitube bundles are easy to fit and remove and thus enable tube side cleaning in fouling situations. Inserts such as twisted tape, wire coils, ribs, and dimples mainly obstruct the flow and separate the primary flow from the secondary flows. This causes the enhancement of the heat transfer in the tube flow. Inserts reduce the effective flow area thereby increasing the flow velocity. A complete uncertainty analysis was also made to estimate the errors associated with experiments.

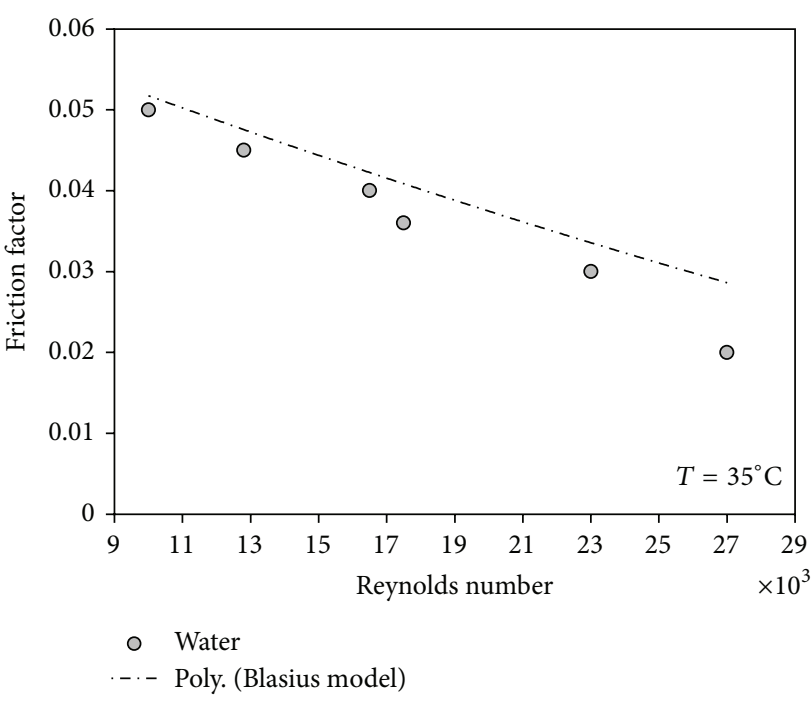

FIGURE 9: Comparison between measured friction factor and that calculated from Blasius equation [17].

The individual uncertainties related to different instruments involved in the experiment were first evaluated to calculate the maximum possible error in Reynolds number and friction factor. The maximum uncertainties of Reynolds number and friction factor were found to be $1.4 \%$ and $4.2 \%$, respectively. The uncertainties in temperature measurement of the inlet and outlet for nanofluid and base fluid were about $\pm 0.15 \%$ and $\pm 0.20 \%$. The uncertainty in the pressure measurement was estimated to be less than $\pm 2.5 \%$.

It should be noted that the pressure drop of the fluid flow is one of the main parameters in determining the performance of the nanofluid as the hot fluid. In calculating the pressure drop, the density, viscosity, and friction factor of the fluid must be taken into consideration. When using a fluid with high density and viscosity, this pressure drop increases. Therefore, this is one of the disadvantages of using nanofluid as the heat transfer fluid. So in this study, the friction factor, pressure drop, and efficiency of titanium oxide nanofluid have been calculated and results have been provided in Figures 9-12. For example, Figure 9 represents the obtained values of the friction factor for water at the temperature of $35^{\circ} \mathrm{C}$. Then, these results are compared with the Blasius theoretical model. As expected, the results are in good agreement with the theoretical model. The maximum and minimum errors were $6.5 \%$ and $3.4 \%$, respectively. The friction factor increases with the Reynolds number. As seen in Figures 10 and 11, when using nanofluid, the friction factor and pressure drop are slightly higher than in the base fluid. With the simultaneous use of nanofluid and twisted tape, this amount increases. It can be said that using nanofluid without twisted tape and with twisted tape increases the friction factor and pressure drop to 1.2 and $2.3 \%$ as compared to the base fluid. Since the friction factor is in direct relation to the pressure drop, the pressure drop increases. The obtained values are in good agreement with Duangthongsuk and Wongwises theoretical model. The uncertainties for the nanofluid without and with 


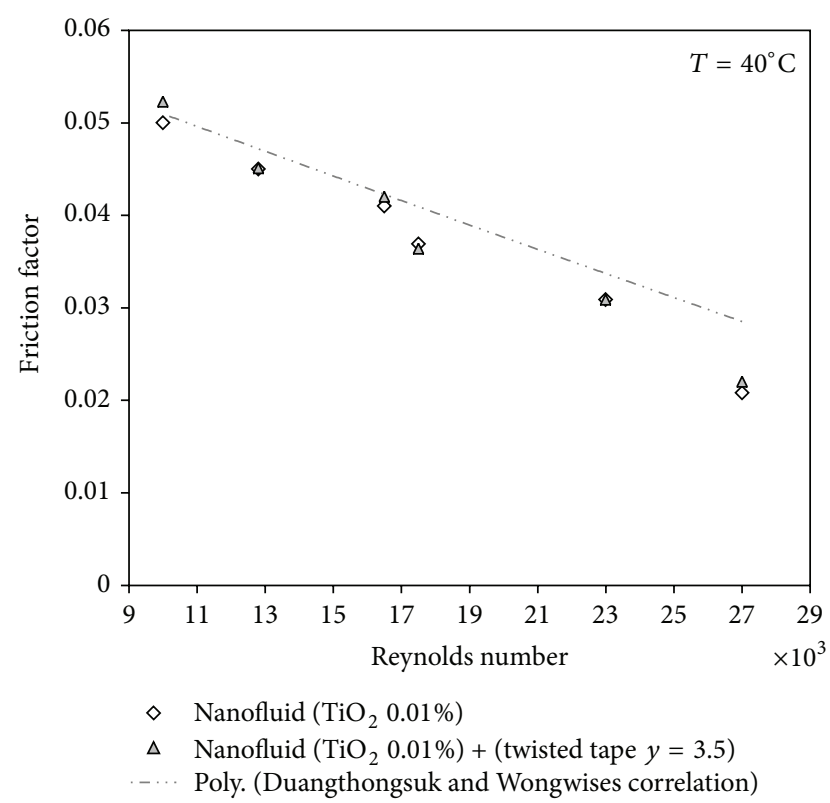

FIGURE 10: Comparison between measured friction factor and that calculated from Duangthongsuk and Wongwises correlation [9].

the twisted tape are 2 and $2.5 \%$ as compared to Duangthongsuk and Wongwises theoretical model. As seen in Figure 12, thermal efficiency is higher when using the nanofluid with twisted tape than when only nanofluid or water is used. The minimum and maximum increase are 10 to $30 \%$. The reasons of the increase in the thermal efficiency can be explained as follows.

(1) Increasing the heat transfer coefficient and thermal efficiency depends on the increase in the fluid thermal conductivity and the decrease in the boundary layer thickness. Nanofluid thermal conductivity increases with the volumetric concentration. The decrease in the boundary layer thickness can be attributed to the mobility of the particles near the wall, migration of the particles towards the tube center, and decrease of the viscosity.

(2) The collisions occurring between nanoparticles and the base fluid molecules on the one hand and the impacts of the particles on the heat exchanger wall, on the other hand, result in an increase in energy.

(3) The friction between the wall and fluid increases if NFs are dealt with and therefore, heat transfer improves.

In the pipe-pipe heat exchangers, due to the high thermal efficiency of nanofluid compared to water, nanofluids can be used in different heating and cooling processes. Therefore, water flow rate can be decreased by increasing the heat transfer. Probably this solves the used water and produced wastewater problems in the big industries such as oil and petroleum. In addition, the dimensions of the heat exchangers can be reduced by increasing the heat transfer. Addition of the nanoparticles into the fluids increases the

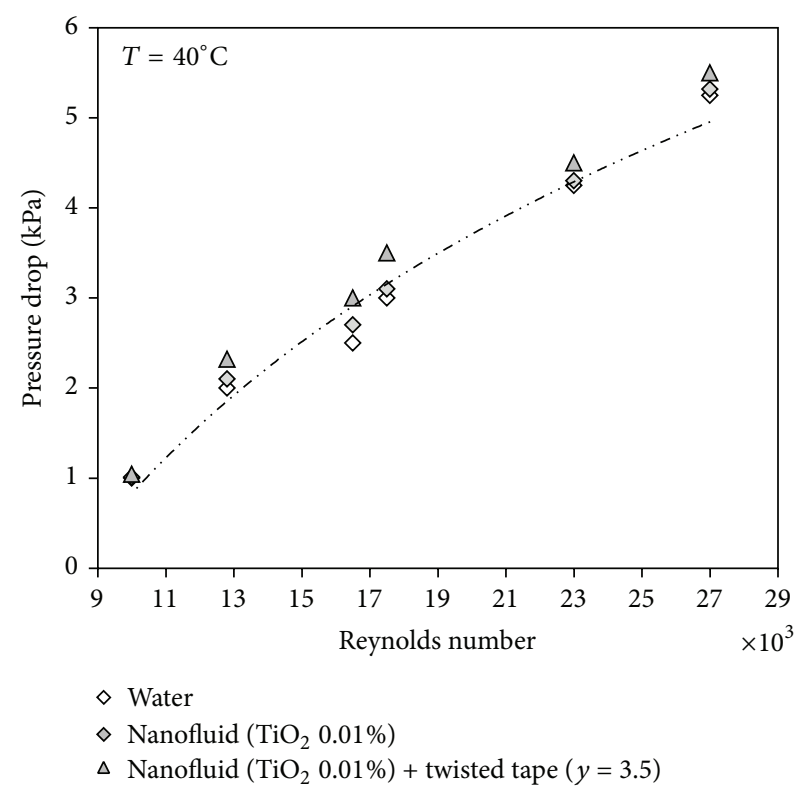

FIGURE 11: The effect of volume concentration and twisted-tape $\mathrm{TiO}_{2}$-water on the pressure drop at different Reynolds numbers.

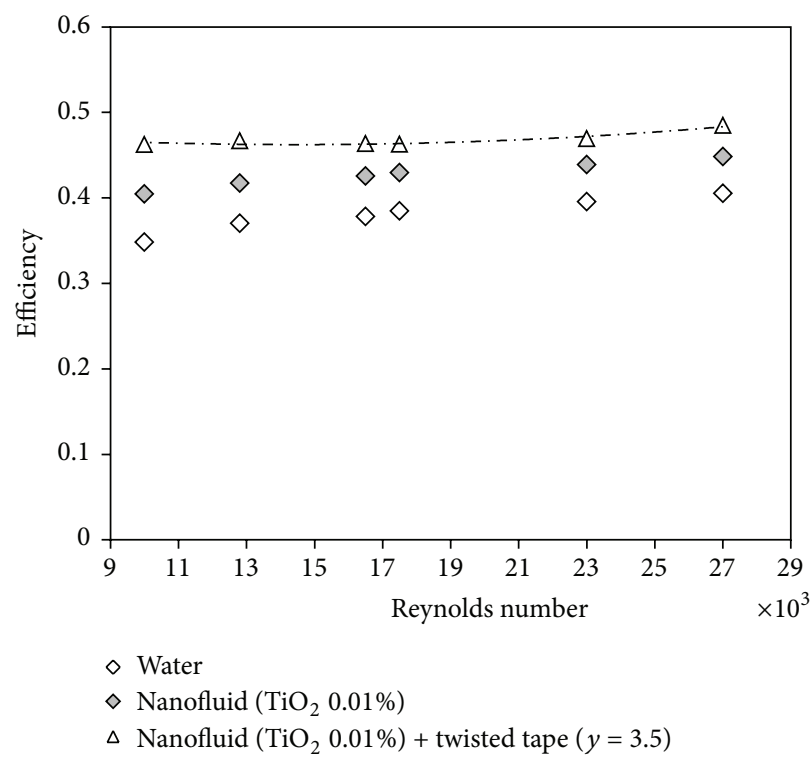

FIGURE 12: The effect of volume concentration and twisted-tape $\mathrm{TiO}_{2}$-water on the efficiency at different Reynolds numbers.

heat transfer coefficient and thereby decreases the operational and production costs. Efficiency increases with the heat transfer. So the power needed for pumping and heat transfer area decrease. This in turn reduces the fixed costs. Also, increasing efficiency controls the transferred heat better and decreases the destructive impacts of energy on the environment. 


\section{Conclusion}

Experimental results obtained with the $\mathrm{TiO}_{2}$ nanofluid heat exchanger and twisted tape with the pitch of 3.5 can be summarized as follows.

(1) Using titanium oxide nanofluid with the volume concentration of $0.01 \%$ in the double pipe heat exchanger with the twisted tape and without the twist tape increases the heat transfer and overall heat transfer coefficient about $12 \%$ and $20 \%$ as compared to the base fluid.

(2) Using titanium oxide nanofluid with the volume concentration of $0.01 \%$ in the double pipe heat exchanger with the twisted tape and without the twist tape increases the efficiency about $10 \%$ and $30 \%$ as compared to the base fluid.

(3) Using titanium oxide nanofluid with the volume concentration of $0.01 \%$ in the double pipe heat exchanger with the twisted tape and without the twist tape increases the friction factor about $2 \%$ and $2.5 \%$ as compared to the base fluid.

(4) Results show that Blasius and Duangthongsuk and Wongwises theoretical models are in good agreement with the experimental data related to the friction factor and the observed uncertainty is low.

\section{Nomenclature}

A: Heat transfer area $\left(\mathrm{m}^{2}\right)$

$C_{p}$ : Specific heat $\left(\mathrm{kJ} \mathrm{kg}^{-1}{ }^{\circ} \mathrm{C}^{-1}\right)$

D: Tube diameter $(\mathrm{m})$

$d$ : Nanoparticle diameter $(\mathrm{m})$

$k$ : Thermal conductivity $\left(\mathrm{W} \mathrm{m}^{-1}{ }^{\circ} \mathrm{C}^{-1}\right)$

$L: \quad$ Tube length $(\mathrm{m})$

$\dot{m}$ : Mass flow rate $\left(\mathrm{kg} \mathrm{s}^{-1}\right)$

Pe: Peclet number (dimensionless)

Pr: Prandtl number (dimensionless)

Q: Heat transfer rate $(\mathrm{W})$

Re: Reynolds number (dimensionless)

T: $\quad$ Temperature $\left({ }^{\circ} \mathrm{C}\right)$

$U$ : Overall heat transfer coefficient $\left(\mathrm{W} \mathrm{m}^{-2}{ }^{\circ} \mathrm{C}^{-1}\right)$

$v$ : Main velocity $\left(\mathrm{m}^{2} \mathrm{~s}^{-1}\right)$

$m$ : Flow consistency index, $\mathrm{s}^{-1}$

$w$ : Tape width, $\mathrm{mm}$

$y$ : Tape pitch length

$n$ : Flow behavior index.

\section{Greek Symbols}

$\Delta T_{\operatorname{lm}}:$ Logarithmic mean temperature difference $\left({ }^{\circ} \mathrm{C}\right)$

$\Delta P: \quad$ Pressure drop, $\mathrm{Pa}$

$\alpha: \quad$ Thermal diffusivity $\left(\mathrm{m}^{2} / \mathrm{s}\right)$

$\rho: \quad$ Density $\left(\mathrm{kg} \mathrm{m}^{-3}\right)$
१: Kinematic viscosity $\left(\mathrm{m}^{2} / \mathrm{s}\right)$

$\varphi_{V}$ : Nanoparticle volume concentration (dimensionless).

Subscripts

in: Inlet

m: Mean

NF: Nanofluid

cf: Cold fluid

out: Outlet

p: Particles

$f$ : Friction factor

bf: Base fluid.

\section{Conflict of Interests}

The authors declare that there is no conflict of interests regarding the publication of this paper.

\section{References}

[1] S. U. S. Choi, "Enhancing thermal conductivity of fluids with nanoparticles," in Developments and Applications of NonNewtonian Flows, D. A. Siginer and H. P. Wang, Eds., vol. 66, FED 452, pp. 99-105, ASME, New York, NY, USA, 1995.

[2] R. Aghayari, H. Maddah, F. Ashori, A. Hakiminejad, and M. Aghili, "Effect of nanoparticles on heat transfer in mini doublepipe heat exchangers in turbulent flow," Heat and Mass Transfer, 2014.

[3] W. Duangthongsuk and S. Wongwises, "Heat transfer enhancement and pressure drop characteristics of $\mathrm{TiO}_{2}$-water nanofluid in a double-tube counter flow heat exchanger," International Journal of Heat and Mass Transfer, vol. 52, no. 7-8, pp. 20592067, 2009.

[4] B.-H. Chun, H. U. Kang, and S. H. Kim, "Effect of alumina nanoparticles in the fluid on heat transfer in double-pipe heat exchanger system," Korean Journal of Chemical Engineering, vol. 25 , no. 5, pp. 966-971, 2008.

[5] W. Duangthongsuk and S. Wongwises, "Effect of thermophysical properties models on the predicting of the convective heat transfer coefficient for low concentration nanofluid," International Communications in Heat and Mass Transfer, vol. 35, no. 10, pp. 1320-1326, 2008.

[6] A. K. Santra, S. Sen, and N. Chakraborty, "Study of heat transfer due to laminar flow of copper-water nanofluid through two isothermally heated parallel plates," International Journal of Thermal Sciences, vol. 48, no. 2, pp. 391-400, 2009.

[7] P. K. Namburu, D. K. Das, K. M. Tanguturi, and R. S. Vajjha, "Numerical study of turbulent flow and heat transfer characteristics of nanofluids considering variable properties," International Journal of Thermal Sciences, vol. 48, no. 2, pp. 290 302, 2009.

[8] I. Gherasim, G. Roy, C. T. Nguyen, and D. Vo-Ngoc, "Experimental investigation of nanofluids in confined laminar radial flows," International Journal of Thermal Sciences, vol. 48, no. 8, pp. 1486-1493, 2009. 
[9] W. Duangthongsuk and S. Wongwises, "An experimental study on the heat transfer performance and pressure drop of $\mathrm{TiO}_{2}$ water nanofluids flowing under a turbulent flow regime," International Journal of Heat and Mass Transfer, vol. 53, no. 1-3, pp. 334-344, 2010.

[10] M. Hojjat, S. G. Etemad, R. Bagheri, and J. Thibault, "Convective heat transfer of non-Newtonian nanofluids through a uniformly heated circular tube," International Journal of Thermal Sciences, vol. 50, no. 4, pp. 525-531, 2011.

[11] M. Hojjat, S. G. Etemad, R. Bagheri, and J. Thibault, "Rheological characteristics of non-Newtonian nanofluids: experimental investigation," International Communications in Heat and Mass Transfer, vol. 38, no. 2, pp. 144-148, 2011.

[12] H. Heidary and M. J. Kermani, "Heat transfer enhancement in a channel with block(s) effect and utilizing Nano-fluid," International Journal of Thermal Sciences, vol. 57, pp. 163-171, 2012.

[13] N. Pelević and T. H. van der Meer, "Numerical investigation of the effective thermal conductivity of nano-fluids using the lattice Boltzmann model," International Journal of Thermal Sciences, vol. 62, pp. 154-159, 2012.

[14] M. Fakoor-Pakdaman, M. A. Akhavan-Behabadi, and P. Razi, "An empirical study on the pressure drop characteristics of nanofluid flow inside helically coiled tubes," International Journal of Thermal Sciences, vol. 65, pp. 206-213, 2013.

[15] P. Naphon and T. Suchana, "Heat transfer enhancement and pressure drop of the horizontal concentric tube with twisted wires brush inserts," International Communications in Heat and Mass Transfer, vol. 38, no. 2, pp. 236-241, 2011.

[16] K. Wongcharee and S. Eiamsa-Ard, "Heat transfer enhancement by using $\mathrm{CuO} /$ water nanofluid in corrugated tube equipped with twisted tape," International Communications in Heat and Mass Transfer, vol. 39, no. 2, pp. 251-257, 2012.

[17] R. B. Bird, W. E. Stewai, and E. N. Lightfoot, Transport Phenomena, John Wiley \& Sons, 2nd edition, 2002.

[18] B. C. Pak and Y. I. Cho, "Hydrodynamic and heat transfer study of dispersed fluids with submicron metallic oxide particles," Experimental Heat Transfer, vol. 11, no. 2, pp. 151-170, 1998.

[19] C. T. Nguyen, G. Roy, C. Gauthier, and N. Galanis, "Heat transfer enhancement using $\mathrm{Al}_{2} \mathrm{O}_{3}$-water nanofluid for an electronic liquid cooling system," Applied Thermal Engineering, vol. 27, no. 8-9, pp. 1501-1506, 2007.

[20] S. U. S. Choi, "Enhancing thermal conductivity of fluids with nanoparticles," in Proceedings of the ASME International Mechanical Engineering Congress and Exposition, pp. 99-105, November 1995.

[21] G. K. Batchelor, "The effect of Brownian motion on the bulk stress in a suspension of spherical particles," Journal of Fluid Mechanics, vol. 83, no. 1, pp. 97-117, 1977. 

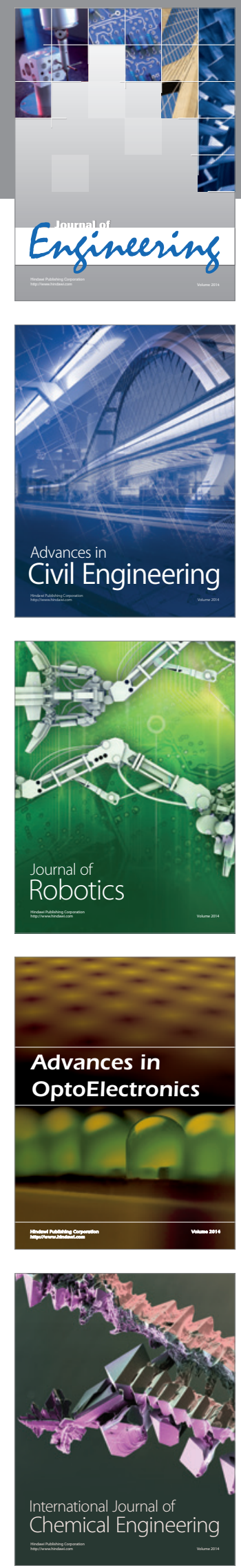

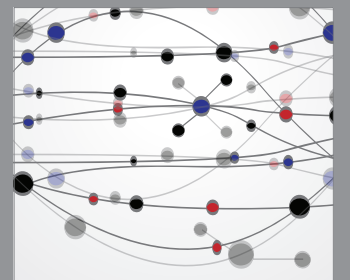

The Scientific World Journal
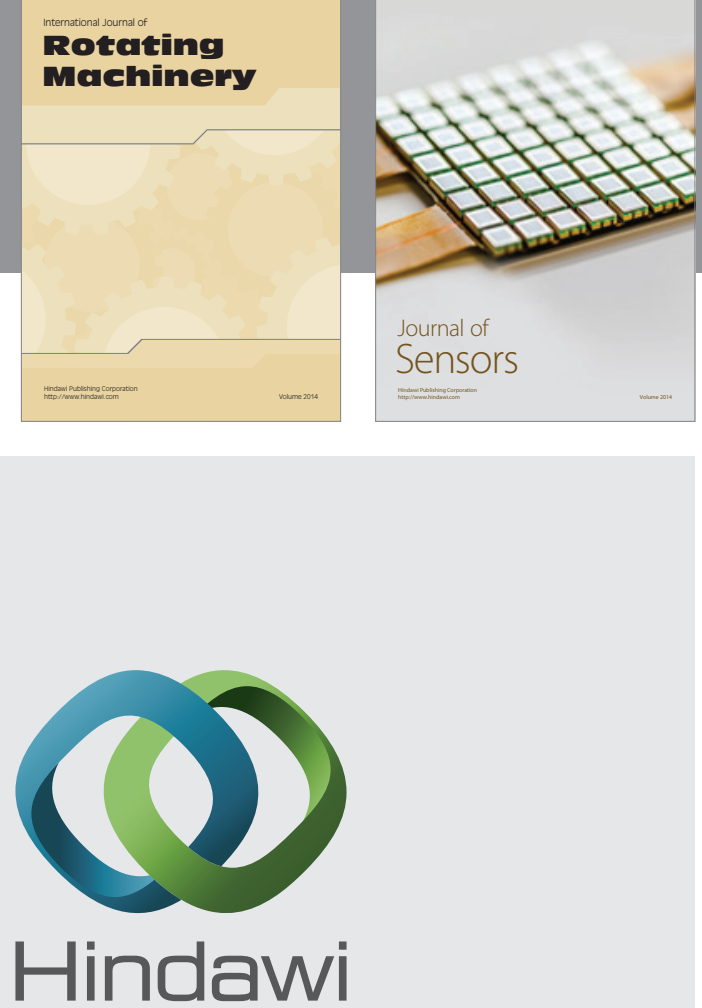

Submit your manuscripts at http://www.hindawi.com
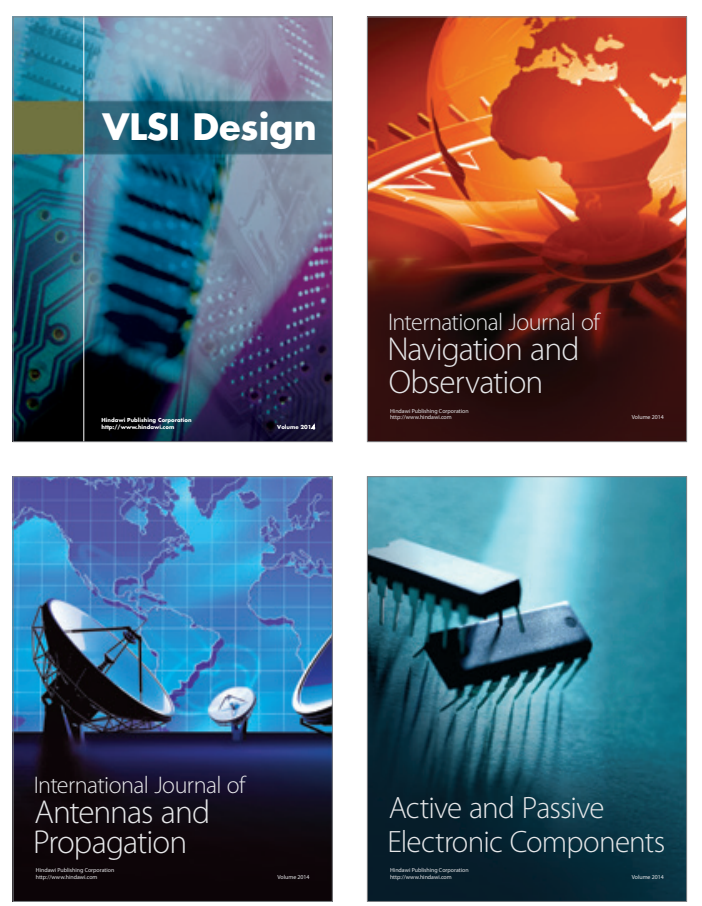
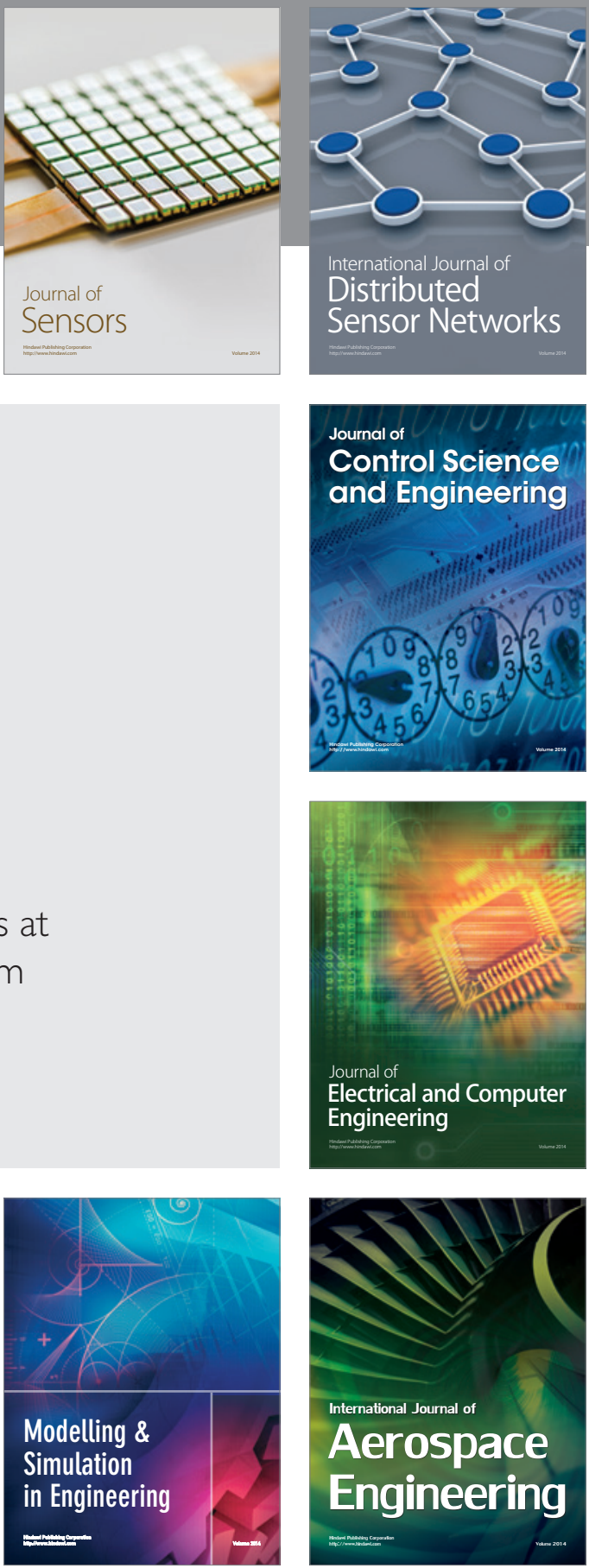

Journal of

Control Science

and Engineering
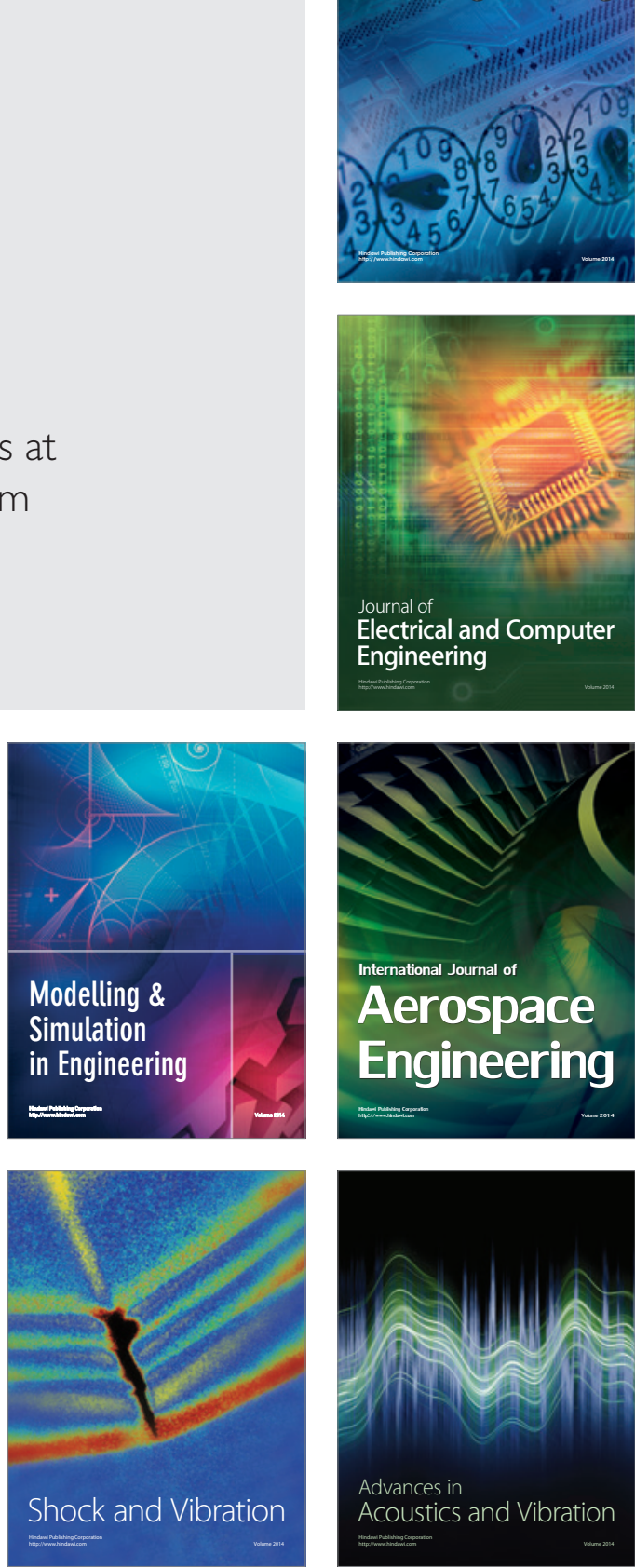